\title{
Chapter 10 \\ Expert Systems for Assessing Disaster Impact on the Environment
}

\author{
Mykola M. Biliaiev, N. Rostochilo, and M. Kharytonov
}

\begin{abstract}
This paper presents expert systems and the numerical models to simulate atmosphere pollution after accidents with toxic substances. The expert systems allow one to assess impact on the person or environment after accidents of different types at chemical enterprises or storages. The process of toxic gas dispersion in the atmosphere is computed using the convective-diffusive equation. To compute the flow field among the buildings, two fluid dynamic models are used. The first fluid dynamic model is based on the 3-D equation of the potential flow. The second fluid dynamic model is based on the 2-D equations of the inviscid separated flows. To solve the convective-diffusive equation of the toxic gas dispersion in the atmosphere, the implicit change-triangle difference scheme is used. To solve the equations of the fluid dynamic models the A.A. Samarski's difference scheme of splitting and change-triangle scheme are used. The developed numerical models have two submodels. The first submodel was developed to simulate the process of the atmosphere pollution after the accident spillages and the evaporation of the toxic substance from the soil. The second submodel allows predicting the air pollution inside the rooms in the case of the outdoor toxic gas infiltration into the room. The developed systems allow assessing the safety of the evacuation route. The developed expert system can be used to solve some specific problems such as the assessment of efficiency of protection measures which are developed to reduce the negative impact on the environment.
\end{abstract}

M.M. Biliaiev $(\varangle) \bullet$ N. Rostochilo $\bullet$ M. Kharytonov

Dnipropetrovsk National University of Railway Engineering,

Lazaryana Str. 2, Dnipropetrovsk 49010, Ukraine

e-mail: envteam@ukr.net 



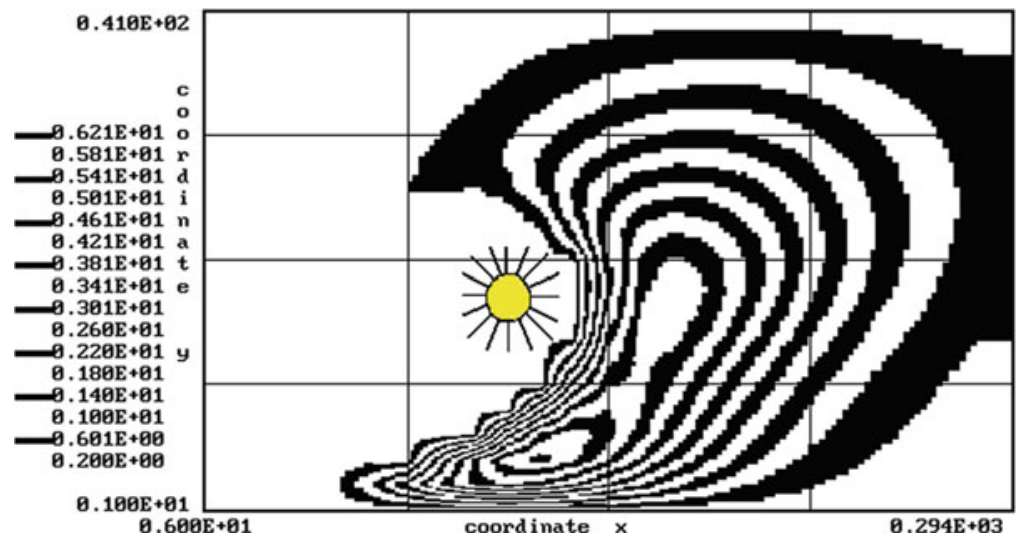

Fig. 10.11 Concentration of $\mathrm{NH}_{3}$ (section $\left.Y=138 \mathrm{~m}\right) t=12 \mathrm{~s}$ (with neutralization)

Table 10.1 Mass of the eliminated $\mathrm{NH}_{3}$

\begin{tabular}{lrrrr}
\hline$t$, sec & 12 & 16 & 20 & 26 \\
Mass of $\mathrm{NH}_{3}, \mathrm{~kg}$ & 129 & 213 & 271 & 317 \\
\hline
\end{tabular}

\subsection{Conclusions}

We have presented the expert systems to predict the disaster impact on the person or environment in the case of accidents at chemical enterprises or storages. The expert systems are based on the numerical integration of the convective-diffusive equation and the equations of two fluid dynamic models. The developed numeric models allow predicting the atmosphere pollution among the buildings. Application of the expert systems for solving some problems in the field of the environmental safety was shown.

\section{References}

1. Belayev NN (1999) Computer simulation of the pollutant dispersion among buildings. In: Belayev NN, Kazakevitch MI, Khrutch VK (eds) Wind engineering into 21st century: proceedings of the tenth international conference on wind engineering, Copenhagen (Denmark). A. A. Balkema, Rotterdam/Brookfield, pp 1217-1220

2. Belyaev NN, Lisnyak VM (2012) Accident in chemically dangerous object: numeric modeling of the toxic gas neutralization process under building roof. News Dnipropetr Natl Univ Railw Transp 40:151-155 (in Russian) 